\title{
Liturgia online na pandemia: reflexões sobre as práticas religiosas de católicos e luteranos no Brasil
}

\author{
Online liturgy in the pandemic: reflection son
}

Religious practices of Catholics and Lutherans in Brazil

\author{
Júlio Cézar Adam* \\ Moisés Sbardelotto**
}

https://doi.org/10.29327/256659.12.1-4

\begin{abstract}
Resumo
Com a pandemia da Covid-19 e fechamento dos espaços de culto no Brasil, as diferentes igrejas buscaram atender seus membros principalmente através da oferta de cultos e serviços religiosos online. Diante desse cenário, este artigo reflete sobre as práticas religiosas e litúrgicas da Igreja Católica Apostólica Romana (ICAR) e da Igreja Evangélica de Confissão Luterana no Brasil (IECLB). São descritos e analisados as mensagens e documentos emitidos durante o periodo pela Conferência Nacional dos Bispos do Brasil (CNBB), no caso da ICAR, e as cartas pastorais emitidas pela presidência da IECLB entre março e julho de 2020. Por fim, conclui-se que a pandemia levou as igrejas a refletirem sobre o sentido teológico e pastoral da prática litúrgica em outros formatos, reconhecendo o digital também como "lugar teológico". Daí a necessidade de fazer teologia das redes, para as redes e nas redes, assumindo o desafio de promover uma "inculturação digital".
\end{abstract}

Palavras-chave: Práticas religiosas.Liturgia.Culto.Internet.Ambiente digital.Inculturação digital.

\begin{abstract}
Withthe Covid-19 pandemic and the closing ofwor shipspaces in Brazil, thedifferentchurchessoughtto serve theirmembersmainlybyoffering online religiousservices. In front ofthissituation, thispaperreflectsonthereligiousandliturgicalpracticesofthe Roman CatholicApostolicChurchandtheEvangelicalChurchofLutheranConfession in Brazil. It describesandanalysesthemessagesanddocumentsissuedduringtheperiodbytheNationalCo nferenceofBishopsofBrazil (CNBB), in the case of ICAR, andthe pastoral lettersissuedbythe IECLB presidency between Marchand July 2020. Finally, it is concludedthatthepandemicledthechurchestoreflectonthetheologicaland pastoral senseofliturgicalpractice in otherformats, recognizingthe digital also as a "theologicalplace."Hencetheneedto do theologyofthe networks, for the networks, andonthe networks, takingonthechallengeofpromoting a "digital inculturation."
\end{abstract}

Keywords: Religiouspractices. Liturgy.Cult. Internet.Digital environment. Digital inculturation.

\footnotetext{
* Doutor em Teologia pela Universidade de Hamburgo, Alemanha e professor adjunto de Teologia Prática na Faculdades EST (São Leopoldo, RS). E-mail: julio3@est.edu.br.

${ }^{* *}$ Doutor em Ciências da Comunicação pela Universidade do Vale do Rio dos Sinos (Unisinos), com estágio de pesquisa doutoral na Universitàdi Roma "La Sapienza", em Roma. É membro do Grupo de Reflexão sobre Comunicação da Conferência Nacional dos Bispos do Brasil (CNBB). E-mail: m.sbar@yahoo.combr.
} 


\section{Introdução}

Vivemos uma pandemia com consequências ainda não vistas pela maioria das gerações contemporâneas. Altamente contagiosa e muito prejudicial para determinados grupos de pessoas, a Covid-19 se espalhou a partir da China, no fim do ano de 2019 e início de 2020, sem dar tempo aos órgãos de saúde e governos para desenvolver uma vacina ou mesmo medicamentos para combater a doença. O único meio de frear seu avanço e evitar o colapso dos sistemas de saúde foi o isolamento físico (OPAS, 2021). Alguns países sofreram mais com a pandemia que outros. O Brasil foi um dos mais afetados. Mesmo com medidas de isolamento adotadas no país, até meados de fevereirode 2021 mais de 228mil pessoas haviam perdido suas vidas no Brasil por causa da Covid-19.

Certamente são vários os motivos, muitos inclusive desconhecidos, que levaram países como Brasil a enfrentar a pandemia com resultados tão drásticos. Cremos que dois motivos, porém, parecem ter contribuído para tal resultado. A situação de precariedade e vulnerabilidade social da maioria da população brasileira, somada à falta de suporte social adequado por parte do Estado, tornou o distanciamento e o isolamento inviáveis para muitas pessoas, principalmente as mais pobres. O segundo motivo tem relação com a postura de negação da pandemia e suas consequências adotada pelo governo federal. Esta postura gerou e reforçou a confusão na orientação da população com respeito às medidas de proteção e o tratamento adequado da doença. O presidente Jair Bolsonaro se posicionou contrário ao seu próprio Ministério da Saúde, inclusive demitindo dois de seus ministros, e até mesmo às orientações da própria Organização Mundial da Saúde (OMS).

Inclusive em relação ao fechamento ou não dos espaços de culto havia posições diferentes. Enquanto o governo federal, pressionado por determinadas igrejas, defendia a continuidade dos cultos, governos regionais e o setor da saúde determinaram o seu fechamento.Gerou-se diante da pandemia uma polarização política, algo muito evidente no país desde as eleições de 2018. Defender o isolamento social e as medidas de proteção significava se posicionar contra o governo.

Apesar das diferentes posições e da polarização, igrejas e espaços religiosos foram interditados a partir de março até meados de setembro de 2020. Diante desta determinação, as diferentes igrejas buscaram atender seus membros das mais diferentes formas, principalmente através da oferta de cultos e serviços religiosos online. 
Este texto pretende descrever essa situação considerando especialmente as práticas religiosas e litúrgicas da Igreja Católica Apostólica Romana (ICAR) e da Igreja Evangélica de Confissão Luterana no Brasil (IECLB) ao longo do período mais crítico da pandemia em 2020. Com isso, buscaremos entender como cada igreja respondeu, no contexto brasileiro, à inédita experiência de "confinamentolitúrgico" mundial provocado pela Covid-19. No caso da ICAR, serão analisados principalmente as mensagens e documentos emitidos durante o período de quarentena pela Conferência Nacional dos Bispos do Brasil (CNBB), instância máxima da Igreja no país. No caso da IECLB tomar-se-á como base principal as cartas pastorais emitidas pela presidência da igreja entre março e julho de 2020. No último ponto, apresenta-se uma breve reflexão sobre a liturgia e práticas religiosas pós-pandemia.

\section{O contexto religioso e eclesial brasileiro}

O contexto brasileiro é marcado pela religião e por práticas religiosas, sendo o culto uma das principais formas de expressão dessa realidade. A religião faz parte da cultura, da sociedade, da intimidade, da política e da economia, da cultura pop, do cotidiano.

Quanto às denominações cristãs, podemos organizar as igrejas da seguinte forma: com o maior número de fiéis, temos a Igreja Católica Apostólica Romana (ICAR), com variadas formas eclesiais, como o catolicismo popular, presente no contexto desde a colonização portuguesa e espanhola; em seguida temos o complexo e diverso grupo das denominações pentecostais e neopentecostais, surgidos no início do século XX; no terceiro grupo estão as igrejas do protestantismo histórico, de origem missionária ou de imigração, que efetivamente entraram em cena a partir do século XIX (Adam, 2016, p. 12).

A Igreja Católica Apostólica Romana confunde-se com a história do Brasil atual, desde o início da colonização portuguesa, no século XVI. A Igreja chegou junto com os missionários que acompanhavam os exploradores da então "Ilha de Vera Cruz". Os colonizadores chegaram ao atual Brasil no dia 22 de abril de 1500 , e poucos dias depois, no dia 26 , foi celebrada a primeira missa por Henrique de Coimbra, frade e bispo português. Desde o início da colonização, o catolicismo teve uma importância fundamental no país, funcionando como um verdadeiro terceiro poder, ao lado do poder espiritual do papa e dos clérigos e do poder temporal do rei e seus conselheiros, arraigando-se na vida pública e social em geral (Hoornaert, 1974). 
Atualmente, o Brasil é considerado o maior país do mundo em número de católicos nominais. Em termos quantitativos, os dados apontam para uma redução histórica do número de católicos no território brasileiro: em 1872, 99,7\% da população brasileira era católica; já em 2010, 64,6\% dos brasileiros permaneciam católicos (dados mais recentes segundo o Censo do Instituto Brasileiro de Geografia e Estatística) (IBGE, 2010).Apesar dessa queda, ainda hoje a Igreja Católica continua sendo a mais numerosa do país.

Entretanto, para além dos dados estatísticos, o importante é "distinguir a evidência dos números sobre os católicos da tradição e presença do catolicismo como referência cultural no Brasil", porque, apesar da diminuição da população católica, "não se pode afirmar que o catolicismo deixou de figurar como uma das referências religiosas estruturantes da nacionalidade e da cultura nacionais" (Steil; Toniol, 2013, p. 224). Em seu interior, contudo, o catolicismo no Brasil apresenta uma grande complexidade e diversidade. O traço constitutivo de sua configuração é a pluralidade: não dá para situar o catolicismo brasileiro em um quadro de homogeneidade (Teixeira, 2005, p.17).

Para Faustino Teixeira, "existem muitos 'estilos culturais de ser católico', como vêm mostrando os estudiosos que se debruçam sobre esse fenômeno. São malhas diversificadas de um catolicismo, ou se poderia mesmo falar em catolicismos" (Teixeira, 2005, p.17). Segundo o autor, as principais "malhas do catolicismo" são um catolicismo "santorial", voltado ao culto aos santos e às devoções populares; um catolicismo "erudito ou oficial", que se encontra em crise atualmente; um catolicismo dos "reafiliados", marcado pela inserção em um "regime forte" de experiência religiosa, como a Renovação Carismática Católica (RCC) e as Comunidades Eclesiais de Base (CEBs); e um catolicismo midiático, com forte presença nos principais meios de comunicação social, e um de seus principais frutos são os chamados "padres cantores", com grande visibilidade midiática no país (dentre eles, poderíamos destacar o Pe. Marcelo Rossi e o Pe. Fábio de Melo, com milhões de cópias de CDs, DVDs e livros vendidos).

Já a Igreja Evangélica de Confissão Luterana no Brasil (IECLB) faz parte do chamado protestantismo histórico e entra neste contexto através de um movimento migratório da Alemanha para o Brasil, a partir da primeira metade do século XIX. (IECLB, 2020a) A IECLB se organiza a partir de comunidades e sínodos em 1968. A igreja é hoje minoritária no contexto brasileiro, contando com a 
aproximadamente 700 mil membros, organizados em 1800 comunidades, contando com em torno de 800 ministros pastores, diáconos, catequistas e missionário, em 18 sinodos (IECLB, 2020b). Como resultado do movimento migratório, a maior parte de seus membros está concentrada na região sul do Brasil.

Em especial, na década de 1970, a IECLB passou por uma mudança paradigmática, na qual se buscou deliberadamente ser uma igreja brasileira, assumindo desafios sociais e a aproximação com outras denominações cristãs. $\mathrm{Na}$ década de 1980, impulsionado por movimentos de renovação litúrgica, principalmente do Conselho Mundial de Igrejas e da Federação Luterana Mundial, se deu início a um criterioso processo de renovação da liturgia com o intuito de torná-la mais relevante, viva, ecumênica, contextual e inculturada (Adam, 2017, p. $1-13)$.

Diante desse contexto, vejamos como cada igreja aqui abordada respondeu à pandemia em suas práticas litúrgicas e religiosas.

\section{Práticas litúrgicas e religiosas na pandemia na IECLB}

J. J. von Allmen defende a tese de que o culto é o coração da vida da Igreja (Allmen, 2006). Tudo que uma igreja faz, parte de seu culto e retorna a ele. Dito de outra forma, a igreja pode prescindir de várias de suas atividades, grupos, projetos, mas não consegue não celebrar. Esta tese se tornou muito verdadeira nos tempos de pandemia e isolamento social. Para muitos cristãos e cristãs, era inconcebivel não celebrar a Páscoa, evento fundante da Igreja cristã. Justamente diante de tamanha crise humana e social, como a pandemia, tornava-se ainda mais necessário, para diversas lideranças cristãs, promover momentos de escuta da Palavra de Deus, de comunicação do Evangelho, de oração em comunidade. Tornava-se ainda mais urgente nas comunidades a necessidade e de buscar a Deus e a religião diante da tragédia da Covid-19. No caso do culto cristão, era imperativo acompanhar as comunidades na experiência do amor cristão para atravessar esse "vale da sombra da morte" (cf. Salmo 23).A religião tem um papel fundamental em situações de crises sociais e traumas coletivos, como a pandemia. Justamente por causa do distanciamento social este papel precisou ser desempenhado de outra maneira.

Diante dessa necessidade e dessa urgência, no caso da IECLB, lideranças, ministros e ministras, musicistas e liturgistas, lançaram mão dos recursos de 
mídia para celebrar a vida, cuidar das pessoas e comunicar o Evangelho.Deve-se dizer que o uso de recursos midiáticos tecnológicos na IECLB era até então algo muito discreto e que muitos ministros e ministras não só nãotinham formação para o uso desses recursos, como resistiam ao seu uso.Diante disso, o principal centro de formação teológica da IECLB, a Faculdades EST, lançou em meados do mês de abril um curso online para ministros e ministras da igreja com reflexão e instruções litúrgicas, práticas e técnicas de como realizar celebrações online (EST, 2020). O curso teve uma adesão muito ampla das lideranças ministeriais. Surpreendentemente em semanas e meses as ofertas de serviços online como cultos, mensagens, lives, podcasts inundaram a rede, levando, inclusive, a uma discussão sobre a qualidade teológica e pastoral desses recursos.

A presidência da igreja, em conjunto com os pastores e pastoras sinodais, reuniu-se a partir de março de 2020 semanalmente para deliberar sobre o funcionamento da igreja frente ao desenvolvimento da pandemia, se pronunciando principalmente em relação à prática dos cultos e serviços litúrgicos. Isso foi feito através da emissão de cartas pastorais às lideranças eclesiais e às comunidades.

Estas cartas além de orientar sobre os cultos e atividades, se posicionam claramente a favor do isolamento social e pelo cancelamento dos cultos e atividades presenciais, algo complexo em um contexto de polarização política como o do Brasil. Já numa das primeiras cartas emitidas, em 17 de março, se percebe claramente esta posição: "Diante do agravamento do quadro, Presidência, Pastoras Sinodais e Pastores Sinodais da IECLB orientam a suspensão imediata, e por tempo indeterminado, de todas as atividades comunitárias que envolvem encontro presencial de pessoas, sejam elas de qualquer idade." (IECLB, 2020c, p. 1). Diante da falta de informações claras do governo, a carta traz explicações sobre a Covid 19, como uma forma de justificar a determinação da suspensão das atividades:

É tempo de incerteza, cautela e cuidado. Suspender atividades não é exagero, mas é atitude de responsabilidade com a vida. A propagação do vírus acontece através da proximidade e do contato fisico. Suspendemos as atividades presenciais para evitar consequências desastrosas e trágicas. Agir preventivamente é tarefa de todas as pessoas, comunidades e lideranças. Reforçamos que as orientações e os decretos de qualquer instância governamental a este respeito devem ser obedecidos(IECLB, 2020c, p. 1). 
Nesta carta, a igreja também orienta sobre como proceder nos serviços religiosos, incentivando a oração, o culto doméstico e em pequenos grupos, cultos online, visitação através de aparato tecnológico. No caso dos sepultamentos, orienta a obedecer às determinações das autoridades locais (IECLB, 2020b, p. 1-2).

Já no dia 23 de março, a igreja emite uma nova carta pastoral, desta vez orientando especificamente sobre o sepultamento. A carta reconhece que velórios e sepultamentos são um dos momentos mais importantes para mostrar a solidariedade da comunidade às pessoas enlutadas, mas que com a pandemia a atuação dos membros terá que ser restrita(IECLB, 2020c, p. 1).Seguem-se, então, orientações de como proceder. Em primeiro lugar a carta determina a "seguir as deliberações dos órgãos de saúde e de vigilância sanitária em todas as instâncias (nacional, estadual, municipal)"(IECLB, 2020d, p. 1).

Nas orientações gerais de como proceder, a carta fala em realizar quando possivel os ritos fúnebres em locais arejados, se possivel ao ar livre, com número limitado de pessoas, priorizando o núcleo familiar, observando-se medidas de higiene e evitando contato físico, uso de material como Bíblias, hinários, folhas de liturgia ou canto, além de buscar realizar as celebrações de forma abreviada(IECLB, 2020d, p. 1-2).A carta também traz orientação de higiene aos ministros e ministras e reforça que estes observem a legislação local(IECLB, 2020d, p. 2).

No início de abril, o tema da Eucaristia étratado. Nesse momento, vários cultos online estavam sendo disponibilizados às comunidades, sendo a liturgia organizada a partir de elementos da liturgia de abertura, liturgia da Palavra e de encerramento. A pergunta pela Eucaristia online e algumas tentativas de realizála fizeram a igreja emitir a carta afirmando não haver estudo, condições e elementos suficientes para a celebração online do sacramento.

A situação de crise levantou a pergunta acerca da celebração da Ceia do Senhor através de transmissão online. O assunto foi debatido na reunião virtual entre Presidência, Pastoras Sinodais, Pastores Sinodais e Secretaria Geral da IECLB. Entendemos a preocupação de transmitir a comunhão, o perdão dos pecados e o conforto desse sacramento. Analisamos aspectos favoráveis e adversos à luz da tradição bíblica, da confessionalidade luterana e das transformações sociais advindas com as novas tecnologias. $\mathrm{O}$ assunto é complexo e requer amplo estudo. Concluímos que não há condições e elementos suficientes para aderir a esta modalidade de administração do sacramento.” (IECLB, 2020e, p. 1). 
Diante dessa impossibilidade, a igreja orienta a comunidade a "reforçar a comunhão através da oração, do anúncio da Palavra e de gestos diaconais com as pessoas necessitadas."(IECLB, 2020e, p. 1). Dois dias depois, na Semana Santa, uma nova carta pastoral traz orientação sobre a celebração da Páscoa.

A carta inicia com uma dificil constatação: "Pela primeira vez, não poderemos nos reunir presencialmente nos templos e nos salões de culto. Na melhor das hipóteses, iremos nos encontrar com as pessoas que convivem dentro da mesma casa. [...] Não será possivel a Ceia do Senhor na manhã de Páscoa." (IECLB, 2020f, p. 1). Em seguida, a carta desafia a pensar adiante: "Será diferente, mas não será menos relevante, menos significativo ou menos importante. Deus não está preso a um lugar; sequer está preso ao tempo. Deus está em todo lugar e em todo tempo.”(IECLB, 2020f, p. 1)

Neste período do ano, a Covid-19 havia chegado efetivamente no Brasil e os números de pessoas infectadas e de mortes não paravam de crescer. Dentro e fora da igreja pessoas ainda continuavam negando a gravidade da doença e questionando a necessidade das medidas de proteção. Por isso, a carta reforça também informações sobre a pandemia, tomando uma posição muito clara contra os pronunciamentos e posturas do governo:

Não bastasse a pandemia em si - que vem se anunciando com uma tragédia para o Brasil - tanto social quanto economicamente, ainda precisamos nos ocupar com o entendimento bastante anticientífico de parte do governo brasileiro, o que tem se revelado extremamente perigoso do ponto de vista da epidemiologia. Felizmente, a maior parte das organizações segue as orientações das ciências da saúde (IECLB, 2020f, p. 1).

A carta reforça a determinação pela proibição de reuniões e cultos presencias nas comunidades de todo o país e enaltece as muitas iniciativas de reuniões, cultos e serviços organizados em formatos digitais, virtuais, áudio-videofônicos (IECLB, 2020f, p. 2).

Boa parte dos mais de 800 Ministros e Ministras que atuam nas 1800 Comunidades tem se esforçado em manter contato com seus membros, através de chats, telefonemas, WhatsApp e outros meios. Suas celebrações, orações, cantos e intercessões têm inundado as redes. Muita gente tem sido alcançada, inclusive para além da própria IECLB(IECLB, 2020f, p. 2). 
No final de abril, a igreja emite uma nova carta reforçando a determinação de suspensão de cultos e reuniões de grupos comunitários (IECLB, 2020g, p. 1). Novamente aqui, a carta pastoral informa as pessoas sobre a situação da pandemia, o que aponta para a confusão de informações que a sociedade estava enfrentando.

O número de casos continua crescendo, que a capacidade de testagem é limitada, que há subnotificação de casos e mortes por Covid-19, que a nossa estrutura hospitalar é frágil e não há tratamento $100 \%$ eficaz, a alternativa mais prudente e responsável no momento é manter a suspensão por mais um período. O critério fundamental que seguimos é o cuidado com a vida(IECLB, 2020g, p. 2).

Nesta carta se fala da pressão que autoridades tem sofrido para manter ou suspender atividades públicas. Também ministros e ministras sofrem pressão de seus membros.

Na IECLB, sempre incentivamos a participação no culto e nas demais atividades. Muitas iniciativas foram desenvolvidas para trazer pessoas afastadas ao convivio comunitário. Agora experimentamos o paradoxo de recomendar que as pessoas fiquem em casa, que não venham aos cultos, que não participem de encontros presenciais(IECLB, 2020g, p. 1).

Aqui se constata também que muitas pessoas não estão sendo assistidas com os cultos ou serviços religiosos porque não têm acesso à internet ou a recursos tecnológicos (IECLB, 2020g, p. 2). Também se lança o questionamento se, caso atividades presenciais sejam retomadas, se haveria condições de cumprir todos os protocolos de higiene e proteção e se seria adequado realizar atividades impossibilitando a participação de determinados grupos e pessoas (IECLB, 2020g, p. 2).

A carta de julho é uma carta ampla (sete páginas) de orientação, onde são retomados temas abordados nas cartas anteriores e temas ainda não tratados. A direção da igreja reforça a necessidade do distanciamento social como medida de proteção. Em algumas regiões do país o retorno gradual a atividades presenciais é facultado. Nesta carta fala-se pela primeira vez do Batismo e outros ofícios, como a Bênção Matrimonial, orientando sua realização "avaliar a realização de oficios e Sacramentos levando em conta sua base teológica e confessional e, ao mesmo tempo, considerando a nova realidade, os anseios, as angústias e neces- 
sidades existenciais das pessoas." (IECLB, 2020h, p. 1) Sobre a Eucaristia, apresenta-se elementos da base confessional da igreja sobre o sacramento e reforçase a ideia de que a Ceia Virtual carece de estudo: "Acerca dos pedidos por "Ceia Virtual", consideramos que a questão deve ser refletida sob perspectiva teológica, confessional e pastoral, e a matéria encaminhada à decisão conciliar." (IECLB, 2020h, p. 2).

Em seguida, a carta traz orientações para comunidades onde o culto presencial for possivel. A sugestão da carta é que os cultos sejam breves (em torno de 30 minutos), com pregações breves, com redução do canto comunitário (IECLB, 2020i)e distanciamento físico. Além disso, a carta fala sobre a moldagem da liturgia do culto, reforçando que o culto seja estruturado a partir da liturgia da Palavra. A carta apresenta os principais elementos litúrgicos com uma breve explicação sobre cada um.

\section{Práticas litúrgicas e religiosas na pandemia na ICAR}

No caso da Igreja Católica, a presidência da CNBB manifestou-se com uma mensagem logo no início da pandemia no Brasil, ainda no dia 14 de março de 2020 (CNBB, 2020a). No texto, ao manifestar a sua palavra de esperança e de solidariedade, a CNBB afirmava que "as indicações práticas estão sendo emitidas em cada diocese, considerando e respeitando a realidade", e que tais indicações sobre o modo de celebrar a fé "cabem aos bispos em cada diocese". Entretanto, como órgão representativo da colegialidade episcopal no país, a CNBB também recomendava "atenção e consideração irrestrita às orientações dos especialistas de saúde e autoridades competentes", reconhecendo que "todas as normas visam à proteção das pessoas, buscando evitar a contaminação e preservar a vida".

A mensagem reiterava a necessidade de "evitar aglomerações" como uma das "regras que precisam ser seguidas por todos, com irrestrita atenção e cuidados, a partir da própria consciência, regida pelo bom senso e pela fraternidade". Isso dizia respeito diretamente às celebrações litúrgicas. E a mensagem assumia isso, ao afirmar que "algumas restrições mexem com o nosso jeito de conviver e celebrar, pois somos um povo que traz em si o desejo de sempre estar juntos, tanto nos momentos alegres quanto tristes". Consciente das "restrições ao convívio", a presidência da CNBB reconhecia que "são muitos os recursos tecnológicos ao nosso dispor atualmente. Eles podem ajudar a suprir a distância física nesse período de cautela". 
Portanto, como órgão máximo da Igreja Católica no país, a CNBB não emitiu nenhuma normativa geral, mas deixou nas mãos de cada bispo local a decisão a ser tomada sobre as celebrações litúrgicas, abrindo-se à possibilidade de recorrer aos "recursos tecnológicos" para suprir as limitações do distanciamento. Nesse sentido, várias dioceses brasileiras publicaram notas e decretos dispensando os fiéis da obrigatoriedade de "participar fisicamente" das celebrações dominicais em suas comunidades. A própria CNBB divulgou que, até o dia 26 de março de 2020, 38 arquidioceses e 134 dioceses já haviam suspendido as missas com a presença dos fiéis. Segundo o órgão, "a indicação é acompanhar as celebrações transmitidas pelos meios de comunicação, como televisão, rádio e internet" (CNBB, 2020b).

Diante do ineditismo desse "confinamento litúrgico", a resposta quase automática de inúmeras dioceses, paróquias e movimentos católicos foi, justamente, promover mais transmissões de missa ou outros momentos de reflexão, formação e oração via TV, rádio e internet. Um dos fenômenos mais fortes nesse sentido foram as chamadas "lives" via redes sociais digitais, com momentos de formação e oração. Em muitos casos, percebeu-se um esforço muito grande, por parte de padres, religiosos/as ou leigos/as, muitas vezes diante de várias limitações tecnológicas nas comunidades e regiões locais, para que tais ambientes de encontro pudessem ser oferecidos e, assim, se conseguisse superar o isolamento e encurtar as distâncias.

Como a pandemia chegou ao Brasil em pleno tempo de Quaresma, a CNBB, por meio de sua Comissão Episcopal Pastoral para a Liturgia, também passou a disponibilizar, semanalmente, em formato PDF, um roteiro de "Celebrações em Família do Dia do Senhor". Tais subsídios foram um convite aos fiéis e às famílias, impossibilitados de participar das celebrações em suas comunidades de fé como um dos meios de combate à disseminação do coronavirus, a celebrar o Dia do Senhor em seus lares, "uma vez que pela dignidade do Batismo somos todos um Povo Sacerdotal"(CNBB, 2020c). De acordo com o Pe. Leonardo Pinheiro, assessor da comissão, "acompanhar as missas pela televisão é um dos meios que temos à nossa disposição neste momento, mas celebrar a fé através da Celebração da Palavra de Deus é um meio eficaz de nos unirmos como Igreja neste momento tão dificil e, ao mesmo tempo, cheio de esperança em preparação para a Páscoa" (CNBB, 2020c). 
O roteiro reconhece que o tempo litúrgico da Quaresma "é um forte tempo de oração, escuta da Palavra de Deus e práticas de caridade em vista da celebração da Páscoa do Senhor". Porém, como esse tempo estava sendo vivido "de forma bastante diferente por conta do combate à disseminação do Covid-19”, a Comissão de Liturgia explicava que, "acolhendo a orientação das autoridades civis e sanitárias, nossos bispos no Brasil orientam os fiéis a permanecerem em suas casas, evitando aglomeração de pessoas e, consequentemente não participando das celebrações eucarísticas". Por isso, a CNBB convidava a "celebrar o Dia do Senhor como Igreja doméstica, com nossos familiares, em nossas casas”.

O subsídio também resgatava as "Diretrizes Gerais da Ação Evangelizadora na Igreja do Brasil", documento que norteia as ações de evangelização da Igreja Católica no Brasil, no qual se afirma que "a casa, enquanto espaço familiar, foi um dos lugares privilegiados para o encontro e o diálogo de Jesus e seus seguidores com diversas pessoas". Assim, continuava a explicação da Comissão de Liturgia da CNBB,

\footnotetext{
Desejamos oferecer esta sugestão de Celebração da Palavra de Deus para ser celebrada em sua casa, com seus familiares neste triste momento da pandemia. São muitos os horários de transmissão de missas em nossos canais católicos que podemos acompanhar, mas vivendo a dignidade de povo sacerdotal que nosso batismo nos conferiu podemos não só acompanhar, mas celebrar com nossas famílias o Dia do Senhor. Escolha em sua casa um local adequado para celebrar e rezar juntos. Prepare sua Bíblia com o texto a ser proclamado, um crucifixo, uma imagem ou ícone de Nossa Senhora, uma vela a ser acesa no momento da celebração. (CNBB, 2020d).
}

Tais subsídios continuavam sendo disponibilizados até o momento em que este artigo foi finalizado, em fevereiro de 2021.

$\mathrm{Na}$ primeira fase da pandemia, a mesma Comissão de Liturgia da CNBB também publicou algumas indicações sobre "como se preparar para a missa em casa durante a quarentena imposta pelo coronavirus" (CNBB, 2020e). Sugere-se, por exemplo, preparar a própria casa e criar um "ambiente celebrativo" e se convida a participar "ativa e efetivamente" da liturgia transmitida pelos meios de comunicação. Essa conscientização é importante, pois a mera conexão não significa necessariamente participação. Não se trata de uma ação automática: para 
participar, é preciso agir ativamente, conscientemente. E, para isso, é preciso educar pedagogicamente os fiéis para essas novas formas de participação.

Segundo o texto da CNBB, as missas nos meios de comunicação "se tornam, ainda mais neste momento, instrumentos eficazes de "reunir' todos, cada um em suas casas, sobretudo os idosos, em torno da Palavra de Deus". Dada a centralidade da comunhão física da hóstia consagrada para a fé católica, o convite durante a pandemia foi a fazer a "comunhão espiritual". Segundo o Padre Leonardo José Pinheiro, assessor da Comissão de Liturgia da CNBB,

Todos são chamados, mesmo não comungando concretamente como fariam se estivessem nas celebrações, a fazer sua comunhão espiritual, isto é, no momento da comunhão em suas casas unirem seu coração com toda a igreja cultivando no coração o desejo de estar recebendo o corpo do Senhor e juntando sua prece às preces de toda a Igreja, sobretudo para que se supere logo este momento da pandemia que estamos enfrentando. Estaremos assim unidos pela força da fé e pelas ondas dos meios de comunicação.(CNBB, 2020e)

Destaca-se ainda que "uma forma de estar em oração e em sintonia com a Igreja é por meio da meditação da Liturgia Diária sozinho ou em família”. E, especialmente no tempo da Quaresma que a Igreja estava vivendo, "além da liturgia do dia, é possivel intensificar a leitura e meditação da Palavra de Deus, o terço e a Via Sacra".

Já a Equipe de Análise de Conjuntura Eclesial da CNBB também divulgou um documento intitulado "Pandemia e pós-pandemia: dez pontos para reflexão" (COSTA, 2020). O documento reconhece o "tempo dificil da Pandemia do Novo Coronavírus (COVID-19), em que parece custoso ver a presença do Senhor junto a nós". Baseando-se na narrativa dos discípulos de Emaús, reafirma que, "nas noites escuras da vida e da história, o Senhor permanece conosco, Ele caminha conosco". E, a partir disso, propõe alguns elementos de reflexão sobre o "processo de volta" e o "pós-pandemia".Nesse sentido, o texto afirma, de modo introdutório:

Este tempo grave de Pandemia fechou as portas de nossas igrejas, mas a Igreja não está fechada, ela continua alimentando seus filhos e filhas através da oração, da Palavra, das celebrações transmitidas pelas TVs Católicas, rádios e mídias sociais, continua assistindo aos pobres e mais necessitados pela caridade e criando redes de solidariedade. [...] É preciso, vivermos com res- 
ponsabilidade este momento, incentivando o nosso povo ao cuidado com a própria vida e com a vida do próximo. (COSTA, 2020)

E o primeiro dos dez pontos para reflexão é precisamente sobre a importância da comunicação e das mídias sociais. O texto indica:

Este tempo de Pandemia nos fez estar presentes nas casas e na vida das pessoas de uma forma nova: por meio das mídias sociais. Já as usávamos como meio de comunicação, de evangelização, de missão e de solidariedade. Este tempo acelerou o processo de uso das mídias sociais para reuniões, trabalhos, aulas, missas, etc., tudo on-line. Descobrimos uma nova forma de nos fazermos presentes nas casas, nas famílias e na vida das pessoas. E as pessoas descobriram este novo modo de presença, de participação na vida da comunidade. Este caminho deve continuar a ser trilhado: quantas lives, inclusive com transmissão de celebrações, terços, orações, etc. A PASCOM (Pastoral da Comunicação) tornou-se uma pastoral fundamental na vida das Dioceses, Paróquias e Comunidades. É um passo que foi dado e que não poderá retroceder. [...] Por isso, o uso das mídias sociais deverá continuar a ser um grande elemento da presença da Igreja, de evangelização, demissão, de oração com o nosso povo, de promoção da caridade e solidariedade. Este caminho exigirá maior investimento nas PASCOM, na aquisição de materiais e de formação de pessoas especializadas.(COSTA, 2020).

Assim, percebe-se um forte reconhecimento por parte da Igreja do papel da comunicação digital. Além disso, reafirma-se a complementariedade entre as diversas linguagens eclesiais e litúrgicas: "Não há oposição entre a assembleia litúrgica presencial e a transmissão virtual, pois existe uma absoluta primazia do presencial. Trata-se de uma forma de continuar atingindo tantas pessoas que ainda não se despertaram para a importância de viver e partilhar a fé em comunidade" (COSTA, 2020).

Com a gradual reabertura das igrejas e a retomada de algumas celebrações presenciais, será necessário entender e discernir como se explicitará essa complementariedade. Embora não havendo "oposição" entre tais ambientes e linguagens, há diferenças a serem reconhecidas e respeitadas, inclusive do ponto de vista litúrgico. Nesse sentido, se o período de pandemia foi um momento de "aprender a celebrar a distância", o pós-pandemia será também um período de "reaprender" a celebrar presencialmente e também a distância, resguardando as especificidades de cada tempo e lugar. 


\section{Perspectivas para o pós-pandemia}

A experiência vivida durante a pandemia e as potencialidades trazidas pelo processo de midiatização contemporâneose articularam de forma complexa, seja na IECLB, seja na ICAR, como vimos, apresentando beneficios e também riscos para a vida de fé e as práticas religiosas. Em certos momentos, houve o fomento de um certo automatismo e simplismo das respostas pastorais diante de um cenário sem precedentes como o provocado pela pandemia.

No afã de transmitir celebrações e ritos, por um lado, corre-se o risco de transformar a celebração religiosa em um mero espetáculo, em uma "encenação" a ser exibida, produzindo uma espetacularização da liturgia, chegando até a um "clericalismo midiático". Por outro lado, desponta o risco de esquecer que há uma pessoa do outro lado das telas, e a transmissão deve possibilitar que os fiéis também possam viver a celebração e participar dos ritos religiosos em rede. Isso demanda repensar algumas concepções teológico-litúrgicas dentro da conjuntura contemporânea, conhecer as modalidades de conexão, dominar os recursos das plataformas e as linguagens digitais e, também, formar as pessoas para as novas possibilidades de participação.

Mais do que um foco estreito na transmissão, é preciso levar em conta o processo comunicacional que se estabelece especialmente no ambiente midiático, especialmente digital. Isso não significa menosprezar a qualidade técnica da transmissão: pelo contrário, ela é fundamental para auxiliar o fiel a vivenciar o rito e a experimentar a graça de Deus. Contudo, mais importante ainda é possibilitar a construção de relações interpessoais em rede, e não apenas reunir "pessoas para ouvir" e "pessoas para ver". Particularmente em tempos de crise como a pandemia, é preciso ousadia e criatividade pastorais, mas sempre voltadas para o bem do outro e da comunidade. É melhor evitar avançar tecnologicamente se isso significa retroceder teológica e eclesialmente, por falta de discernimento.

Durante o período de distanciamento e isolamento, a relação que as Igrejas viveram com suas comunidades de irmãos e irmãs de caminhada de fé também ganhou uma nova importância. Foi possivel evidenciar mais claramente que uma comunidade é mais do que uma mera congregação de individuos ou fruto de um mero "individualismo conectado".

Assim, tendo em vista o pós-pandemia, é importante levar em conta as novas formações comunitárias que o período de distanciamento trouxe à tona. A 
Igreja da América Latina do século passado ofereceu ao mundo um dos principais frutos do Concílio Ecumênico Vaticano II, as comunidades eclesiais de base (CEBs), um novo modo de ser Igreja e de experimentar a comunidade. Hoje, poderíamos dizer que estamos diante do surgimento de verdadeiras "comunidades eclesiais digitais" (ou CEDs), que atualizariam, com outros "meios" e em outros "ambientes", a mesma busca e necessidade de experiência religiosa, de vínculo interpessoal e também de cidadania eclesial (SBARDELOTTO, 2017).

As CEDs, assim como as CEBs históricas, apontam para uma eclesialidade "nova-ainda-não-experimentada" em meio às variações históricas das formas comunitárias da Igreja. O ambiente digital, assim, diante do ineditismo deste momento histórico para a Igreja, possibilita novas formações eclesiais e comunitárias em rede, muitas vezes, ultrapassando as configurações espaço-temporais da estrutura eclesiástica local (paróquia, diocese etc.). Isso aponta para uma busca de relações outras em ambientes outros, criando e até inventando, positivamente, experiências de vivência e comunicação da fé.

Em suma, a pandemia, com seu somatório de tensões,levou igrejas como a IECLB e a ICAR a refletirem profundamente sobre o culto, o sentido teológico, confessional e pastoral da prática litúrgica em outros formatos, em especial dos sacramentos e oficios. A pandemia revelou às igrejas a necessidade de reconhecer cada vez mais o próprio digital como um "lugar teológico". Em rede também é possivel encontrar a Deus e o "outro", o irmão e a irmã de fé. Também é possivel viver experiências de comunhão e de comunidade. Mas, para isso, é preciso discernir as possibilidades e os limites da cultura digital, suas luzes e sombras, suas riquezas e pobrezas. Faz-se necessário fazer teologia das redes, para as redes e nas redes. O desafio é, precisamente, promover uma "inculturação digital", que permita atualizar a evangelização nas linguagens e ambientes da comunicação contemporânea.

\section{Referências bibliográficas}

ADAM, Júlio C. LiturgicalFormation, LiberationTheologyandLatin American Culture. StudiaLiturgica, v. 47, n. 1, 2017.pp. 1-13,

ADAM, Júlio C. Pregação em trasição: uma perspectiva homilética desde América Latina e Brasil. InternationaWournalofHomiletics, n. 1, 2016.pp. 11-20.

ALLMEN, J. J. von. O culto cristão: teologia e prática. $2^{\circ}$ ed. São Paulo: Aste, 2006. 
BRASIL. IBGE (org.). Censo 2010: mundo católico. Mundo Católico. 2010. Disponí-vel em: http://migre.me/ddYsQ. Acesso em 19 de outubro de 2020.

CNBB. Celebrar em Família o Dia do Senhor - IV Domingo da Quaresma - Ano A, 21 de março de 2020. Disponível em: https://bit.ly/3mWVaTJ. Acesso em 15 de outubro de 2020.

CNBB (Brasil). Mensagem: tempos de esperança e solidariedade. 2020a. Disponivel em: https://www.cnbb.org.br/cnbb-emite-mensagem-na-qual-pedeobservacao-ir restrita-as-orientacoes-medico-sanitarias/. Acesso em: 15 de março de 2020.

CNBB (Brasil) (org.). Mais dioceses brasileiras suspendem missas com participação dos fiéis e investem na internet. 2020b. Disponivel em: https://www.cnbb.org.br/ mais-dioceses-brasileiras-suspendem-missas-comparticipacao-dos-fieis/. Acesso em 23 de março de 2020.

CNBB (Brasil) (org.). CNBB disponibiliza roteiro da celebração familiar do $4^{\circ}$ Domingo da Quaresma. 2020c. Disponivel em: https://www.cnbb.org.br/cnbbdis ponibiliza-roteiro-da-celebracao-familiar-do-4o-domingo-da-quaresma- 2 /. Acesso em 21 de março de 2020.

CNBB (Brasil). Como se preparar para a missa em casa durante a quarentena imposta pelo coronavirus? 2020e. Disponivel em: https://www.cnbb.org.br/con fira-dias-e-horarios-das-missas-transmitidas-pelas-emissoras-de-tv-de-inspira cao-catolica/. Acesso em 20 de março de 2020.

DOM PAULO CEZAR COSTA (Brasil). Diocese de São Carlos (org.). Pandemia e pós-pandemia: dez pontos para reflexão. dez pontos para reflexão. 2020. Equipe de Análise de Conjuntura Eclesial. Disponivel em: https://www.vaticannews.va/pt/igreja/news/2020-05/pandemia-e-pospandemia-dez-pontos-para-reflexao.html Acesso em 08 de maio de 2020.

FACULDADES EST (Brasil) (org.). Curso de Extensão: comunidades em rede. Comunidades em Rede. 2020. Disponivel em: http://www.est.edu.br/comunida desemrede/. Acesso em 19 de outubro de 2020.

HOORNAERT, Eduardo. Formação do catolicismo brasileiro, 1550-1800: ensaio de interpretação a partir dos oprimidos. Petrópolis: Vozes, 1974.

IECLB (Brasil). IECLB. A caminho em terras brasileiras: a criação de comunidades evangélicas no brasil. A criação de comunidades evangélicas no Brasil. Disponivel em: https://www.luteranos.com.br/conteudo/a-caminho-emterras-brasileiras. Acesso em 19 de outubro de 2020a.

IECLB (Brasil) (org.). Comunidades juntas no caminho. Disponivel em: https:// www.luteranos.com.br/conteudo/comunidades-juntas-no-caminho.Acessoem 19 de outubro de $2020 b$.

IECLB (Brasil). Carta da Secretaria Geral da IECLB no 281.455/20, 12/06/2020c.

IECLB (Brasil). Carta Pastoral da Presidência da IECLB no 281849/20, 06/07/ 2020d. 
IECLB (Brasil). Carta Pastoral da Presidência da IECLB no 280034/20, 17/03/ 2020e.

IECLB (Brasil). Carta Pastoral da Presidência da IECLB $n^{\circ}$ 280035/20, 23/03/2020f.

IECLB (Brasil). Carta Pastoral da Presidência da IECLB $n^{o}$ 280273/20, 04/04/2020g.

IECLB (Brasil). Carta Pastoral da Presidência da IECLB $n^{\circ}$ 280274/20, 06/04/2020h.

IECLB (Brasil). Carta Pastoral da Presidência da IECLB $n^{\circ}$ 280365/20, 24/04/2020i.

OPAS - Organização Pan-Americana de Saúde. Folha informativa COVID-19 Escritório da OPAS e da OMS no Brasil, 03/02/2021. Disponível em: https://www.paho.org/pt/covid19. Acesso em 05 de fevereiro de 2021.

SBARDELOTTO, Moisés. E o Verbo se fez rede: religiosidades em reconstrução no ambiente digital. São Paulo: Paulinas, 2017.

STEIL, Carlos A.; TONIOL, Rodrigo. O catolicismo e a Igreja Católica do Brasil à luz dos dados sobre religião no Censo de 2010. Debates do NER. Porto Alegre: UFRGS, ano 14, n. 24, julho-dezembro de 2013. Disponível em: http://goo.gl/MRGaoc. Acesso em 15 de outubro de 2020.

TEIXEIRA, Faustino. Faces do catolicismo brasileiro contemporâneo. Revista USP.São Paulo: USP, n.67, setembro-novembro de 2005. Disponível em: https://bit.ly/30dhEpT. Acesso em 15/10/2020.

Recebido em 19/10/2020 Aceito para publicação em 05/02/2021 